\title{
Türkiye'de Kütüphane ve Bilgibilimi Araştırmalarında Kuram Kullanımı: Bir İçerik Analizi
}

\author{
Use of Theory in Library and Information Science Research in Turkey: A Content \\ Analysis
}

\author{
Kuramlar dünya dediğimizi yakalamak \\ için ĕgrilmiş ăglardır: Onu rasyonelleştirmek, \\ açıklamak ve üstesinden gelmek \\ için. Biz ise ă̆ın gözünü hep daha ince \\ yapmak için uğraşırız * \\ Karl Popper
}

\section{Hülya Dilek-Kayaoğlu**}

\section{$\ddot{O} z$}

Bir bilim dalının entelektüel kimliğinin düzeyi onun kuram oluşturma kapasitesi ile değerlendirilir. $\mathrm{Bu}$ araştırmanın temel amacı da Türkiye'de kütüphane ve bilgibilimi alanındaki araştırmalarda kuram kullanımını incelemek olarak belirlenmiştir. Araştırmanın veritabanını YÖK Ulusal Tez Merkezi Veritabanında listelenen ve 1983-2019 yılları arasında $B B Y$ bölümlerinde tamamlanmış içeriğine erişim izni olan 366 lisansüstü tez oluşturmaktadır (n=366). Her tez, konusu, kuram adl, kuramın bilimsel kökeni ve kuram kullanım düzeyinin derinliği açılarından içerik analizi yöntemiyle incelenmiştir. Elde edilen bulgulara göre tezlerde 75 kuram adı kullanilmıştır. Tezlerin \%22'sinde en az bir kuram adı geçmektedir. Kullanıcı incelemeleri ve bilgi merkezi ya da kütüphane yönetimi konulu tezler en fazla kuram kullanılan tezlerdir. Bertalanffy'ın genel sistemler kuramı, Wilson'ın bilgi arama davranışı kuramı ve belge yaşam döngüsü kuramı tezlerde en fazla kullanılan kuramlardır. Kuram kullanım düzeyinin ortalaması beş derecelik kuram kullanım modeline göre 2,6'dır. Tezlerde kullanılan kuramların \%58,6'sı toplumsal bilim kökenlidir. \%30,6'sl ise kütüphane ve bilgibilimi kökenlidir. Toplumsal bilim kökenli kuramların çoğunluğu da psikoloji ve yönetim disiplinlerine aittir.

Anahtar Sözcükler: Kuram; kuram kullanımı; kütüphane ve enformasyon bilimi araştırması; içerik analizi; Türkiye.

\begin{abstract}
The level of intellectual identity of a discipline is assessed by its capacity for establishing theories. The main objective of this research is defined as to examine the use of theory in the library and information science in Turkey. The sample of the research consists of 366 graduate theses, which are listed in the HEC National Thesis Center database and completed in the departments of Information Management between 1983-2019, with permission to access their content $(n=366)$. The subjects of the theses, the names of the theories used in the theses, the level of the use of theory, and their scientific origin were examined by the content analysis method. According to the findings, 75 theories are mentioned in the theses, and at least one

\footnotetext{
${ }^{*}$ The logic of scientific discovery. New York: Taylor ve Francis e-Library, 2005. s. 38-39

${ }^{* *}$ Prof. Dr., İstanbul Üniversitesi Bilgi ve Belge Yönetimi Bölümü. E-posta: dilekkayaoglu@gmail.com Prof. Dr., Istanbul University Department of Information Management, Turkey.
}

Geliş tarihi - Received: 15.11 .2019

Kabul tarihi - Accepted: 22.12.2019 
theory is referred in $22 \%$ of the theses. Theses on the subject of user studies and library / information centers are used theories the most. Bertalanffy's general systems theory, Wilson's information behavior theory, and document life cycle theory are the most widely used theories in the theses. The degree of theory use indicates 2.6 in the five-point ratio scale of the Five Degrees of Theory Use Model. 58.6\% of the theories used in these theses are related to social sciences, and 30.6\% of them are about the library and information science. The majority of social science-based theories belong to the disciplines of psychology and management.

Keywords: Theory; theory use; library and information science research; content analysis;

Turkey.

\section{Giriş}

Bilim felsefesine göre, kuramın bir bilim alanında yürütülen araştırmalarda kullanılması o alanın ya da disiplinin akademik olgunluğunun ayırt edici bir özelliğidir (Brookes, 1980; Hauser, 1988; Pettigrew ve McKechnie, 2001). Çünkü, bir disiplinin bilim iddiası geliştirdiği kuramlar üzerinden olmaktadır (Dilek-Kayaoğlu, 2017, s. 131) Ayrıca, kuramın varlığ o alandaki araştırmanın öneminin ve saygınlığının bir göstergesi olarak kabul edilir. Hatta bir inceleme alanında kuramın varlığı, hantal ya da düzensiz veriyi düzenlemeyi ve iletmeyi sağladığı ve toplumsal dünyanın karmaşıklığını basitleştirmeye yardımcı olduğu için kuramın geçerli ya da geçersiz olmasından daha önemli bile olabilir (Van Maanen, 1998, s. xxix).

Kütüphane ve bilgibilimi ${ }^{1}$ kayıth bilgi - insan ilişkisini teknolojiyi de dahil ederek inceleyen uygulamalı bir alandır. Birçok araştırmacı kütüphane ve bilgibilimi alanını yeni kuram oluşturma ya da var olan kuramları geliştirme ve kullanma konusunda yeterli bulmamaktadır. Örneğin, Butler (1933, s. vi-viii) daha 20. yüzyılın ilk yarısında toplumsal bilim alanlarında etkinlik gösteren meslek sahiplerinin bu alandaki bilimsel araştırmalardan yararlanarak kuramlarını ve yöntembilimlerini geliştirme yoluna girdiklerini; kütüphanecilerin ise mesleğin kuramsal yönüne ilgi göstermediklerini üniversitelerin de kütüphanelerde verilen mesleki eğitimle bu duruma katkı sağladığını ileri sürer. 20. yüzyılın sonuna gelindiğinde de benzer sorunlar hâlâ tartışılır. Grover ve Glazier (1986) kütüphane ve bilgibilimi alanında kuramın sınırlı kullanımını temel bir sorun olarak ileri sürer. Onlara göre alandaki araştırmalar dar bir odağa ve parçalanmış bir yapıya sahiptir ve kuramsal temeli oluşturmada yetersizdir; çünkü daha çok pratik sorunları çözmeye yöneliktir. Pierce (1992, s. 641) ise kütüphane ve bilgibilimi alanının özellikle iletişim, eğitim, dilbilimi, yönetim, psikoloji, sosyoloji gibi toplumsal bilimlerden kuram ithal ettiğini belirtmektedir. Alanın kuramsal temellerini geliştirmek üzere başka alanlardan elbette seçerek kuram alınabilir; fakat başka alanların kuramsal temellerini geliştirmeye çalışmak bambaşka bir şeydir. Ona göre alan kuramına benzersiz katkımızın ne olduğu ve neden alan araştırmasına rehberlik eden birleştirici bir kuramın var olup olmadığ öncelikle yanıtlanmalıdır. Järvelin ve Vakkari de (1990, s. 415) alandaki kuramların çoğunlukla belirsiz bulur ve açıklamaya dayalı bilimsel yaklaşımların çok sınırlı olduğunu savunur. Hjørland'a göre ise (1998, s. 607) kütüphane ve bilgibilimi alanı iyi kuramlardan yoksundur. Keseroğlu da (2010) kütüphane ve bilgibilim kuramının ancak onu başka disiplinlerden ayıran bilgisi üstüne kurulabileceğini bunun da bilginin örgütlenmesi, kullanıc bilgisi ve diğer (alan bilgisi) olarak kategorilendirir. Yılmaz da (2017, s. 8) kuramuygulama dengesinin gözetilmesi gereken kütüphane ve enformasyon bilimi gibi alanlar için kuramın uygulamaya yol gösterdiğini uygulamanın da kuramın sınanmasını sağladığını belirtir.

Kütüphane ve bilgibilimi alanının iyi kuramlardan yoksun olması ya da bilimsel yaklaşım ve açıklamalardan yeterince yararlanmayan / "kuramsal olmayan" yapısı çoğunlukla

\footnotetext{
${ }^{1}$ Bilgi aksi belirtilmediği sürece enformasyon karşılığında kullanılmıştır.
} 
mesleki bir uygulama olarak ortaya çıkışıyla ilişkilendirilir. Alan için uygulama sorunları ve teknik eğitim modeli hep öncelikli olmuştur (Järvelin ve Vakkari, 1990; Pierce 1992, s. 641). Yontar da (2004, s. 26) benzer bir düşünceyi öne sürer. Ona göre Dewey ile kütüphane bilimi üniversite düzeyinde örgütlenmiş; fakat mesleki pratiğe ağırlık veren ancak kuramsal zemini zayıf olan bir başlangıç yapılmıştır; bu zayıflığın etkileri alanın kuramsal gelişimini ve kuramsal sorunlarını sonrasında da hep etkilemiştir. $\mathrm{Bu}$ düşünceye katılmamak olanaklı değildir. Uygulamada yaşanan sorunlara çözüm bulmayı hedeflemek ya da öncelemek alanın kuramsal sorunlarının araştırılmasının bir anlamda göz ardı edilemesine yol açmıştır. Bunun yanında, kütüphane ve bilgibilimi alanının kimlik oluşturma sürecinde yaşadığı ve yaşamakta olan değişimler onun kuram oluşturma kapasitesini de etkilemiştir ve etkilemektedir. Daha 19. yüzyılın başında alanın "kütüphane bilimi" ile başlayan ve bilim perspektifini vurgulayan adlandırılması, 20. yüzyılın ikinci yarısında kütüphane ve bilgibilimi adlandırması ile disiplinlerarası bir yapıya bürünmüştür. Kütüphane bilimi ve bilgibiliminin birleşmesinden oluşan bu yeni disiplinlerarası alan birbirlerinden ödünç aldıkları kuram ve yöntemler ile kayıtlı bilgi ile insan ilişkisini teknolojiyi de dahil ederek açıklamak üzere tutarlı bir araştırma gündemi oluşturma kapasitesine sahip olmuştur ve son çözümlemede de otonom bir disiplin iddiasından söz edilebilir. Bununla birlikte günümüz Türkiye'sinde bilgi ve belge yönetimi diye bilinen alan için literatürde -ve fakülte / bölüm adlarında- kütüphane ve bilgibilimleri ya da bilgi bilimleri biçimde çoğul bir adlandırılma yapıldığı da görülür. Dolayısıyla alanın disiplinlerarası yapısı çokdisiplinli bir yapıya doğru evrilmiş gibidir (Dilek-Kayaoğlu, 2017). $\mathrm{Bu}$ çoğulcu yaklaşımla farklı "bilgi bilimleri" bir araya gelmiş olur ve alanın kuramsal çerçevesini çizmek oldukça zorlaşır. Çünkü farklı ontolojik ve epistemolojik özelliklere sahip bu alanlar temel bir araştırma nesnesi etrafında ve belirli bir yöntembilim eşliğinde temel araştırma sorularını belirleyerek bir bilgi birikimi -doğal olarak- oluşturamadıklarından kendi akademik gelenekleri ve araştırma nesne ve yöntemleriyle ve bilgi-insan-teknoloji ilişkisini kendi perspektiflerden incelemektedirler. Otonom bir disiplin kimliği olmadan kuram geliştirmenin zorluğu da açıktır.

Bütün bu eleştirilere karşın kuramın kütüphane ve bilgibilimi literatüründeki varlığını sorgulayan araştırmalar, kuram kullanımında ve yeni kuramların geliştirilmesinde zaman içinde niteliksel bir iyileşme olduğunu konunun daha fazla tartışıldığını göstermektedir Özellikle bilgi (arama) davranışı alt alanı bu konuda daha başarılı görülmektedir (Vakkari, 1998). Fakat literatürde kuramın ne anlama geldiği konusunda bir ortak görüş geliştirilmiş olduğu da ileri sürülemez. Örneğin, Pettigrew ve McKechnie (2001) alanda kullanılan 10'dan fazla kuram tanımına yer verir. Bu tanımlarda, kuram "açıklayıcı kavramlar kümesi" olarak görüldüğü gibi, "şeylerin doğasının betimlenmesi ya da açıklanması" olarak da görülmektedir. $\mathrm{Bu}$ nedenle, kuramın ne olduğu, ne işe yaradığı ve kuramla ilişkili terimlerin neler olduğuna kısa da olsa burada değinmek gereklidir.

\section{Kuram ve ilişkili temel kavramlar}

Kuram terimi, kurmak eyleminden gelir. Parçaları birleştirmek, oluşturmak, inşa etmek yanında düşünmek anlamına da gelir ve teori ile eşanlamlı olarak kullanılır. Teori terimi ise Grekçe theoria'dan gelir. Theoria seyre dalmak, görmek ya da görünür hale getirmek anlamında theatre (tiyatro) terimi ile aynı köktendir ve derin bir düşünmeyi içererek (Yıldırım, 1985) incelenen olgulara yönelik olarak toplanan ve betimlenen verilere yönelik bir açıklama sunar. Türkçe sözlükte kuram "[s]istemli bir biçimde düzenlenmiş birçok olayı açıklayan ve bir bilime temel olan kurallar, yasalar bütünü” olarak tanımlanır (Güncel Türkçe Sözlük). Bates'e göre ise (2009) kuram "belirli bir olgu kümesini açıklamak için sunulan varsayım, ilke ve ilişki sistemidir". Glazier ve Grover'a göre ise (2002, s. 319) kuram, "olgular arasındaki ilişkileri açıklamaya çalışan genellemelerdir" ve dinamik bir süreç olarak araştırma sonuçlarına göre sürekli sınanmakta ve gözden geçirilmektedirler (Grover ve Glazier, 1986, s. 
229). Buckland da (1999) kuramı toplumsal bilimlere uyarlayarak şeylerin doğasına ilişkin geniş bir anlayış ve açıklama ile ilgilendiğini belirtir. Bu tanımlar, yöntembilim (toplumsal bilimlerde) açısından değerlendirildiğinde, bir toplumsal bilim araştırmasında şeylerin dünyasına yönelik olarak nicel ya da nitel verileri toplayan araştırmacı önce onları betimler sonra da onlara bir açıklama getirir. Bu açıklamalar ve ilkeler şeylerin "niçin" olduğuna ilişkin genellemeler ve tahminler içerir ve oluşturulan kuram yeni sınamalara açılır.

Kuram, olgular arasındaki ilişkileri açıklamaya çalışan ve tahminler getiren genellemeler ve ilkeler bütünüdür; bununla birlikte farklı genelleme düzeylerine sahip kuramlar olduğunu ileri süren araştırmalar vardır. Örneğin; Grover ve Glazier (1986) ve Glazier ve Grover (2002) toplumsal bilimler literatürünü gözden geçirerek araştırma, kuram, paradigma ve olgu kavramları arasındaki ilişkileri göstermek amacıyla bir kuram taksonomisi geliştirmiştir. Bu taksonomide hiyerarşik olarak ilerleyen üç ana kuram düzeyi belirlenmiştir. Buna göre, birinci düzey kuram (substantive theory / temel düzey kuram) "uygulamalı bir soruşturma alanı için açıklama sağlayan bir dizi önerme" olarak tanımlanır. Bu düzey, uygulama için yol göstericidir. Örneğin Kuhlthau'un bilgi arama davranışı, kullanıcının sürece yönelik davranış, duygu ve gereksinimlerine yönelik bir açıklama getirmektedir. $\mathrm{Bu}$ açıklama uygulamada da kütüphaneciye yol gösterici olmaktadır. Bir sonraki kuram düzeyine formel kuram denir. Formel kuram formel ya da kavramsal bir sorgulama alan1, yani bir disiplin için açıklama yapan bir dizi önermedir ve bir önceki düzeyden daha geniş bir biçimde genelleştirilebilir. Örneğin, bir disiplinde geliştirilen bir genelleme başka disipline etkin bir biçimde uyarlanabilir. Fakat bu düzey bir kuramın her disipline etkin bir biçimde uyarlanabileceği sonucu çıkarılmamalıdır. Büyük kuram (grand theory) ise, olgular arasındaki ilişkileri açıklamak için disiplinlerin sınırlarını aşan bir dizi kuram veya genelleme olarak tanımlanır ve çeşitli disiplinlere etkin bir biçimde uyarlanabilir.

Öte yandan kuram terimi yanında açıklama gücü olan model terimi de burada tanımlanmalıdır. Bates'e (2009, s. 1-2) göre, model, geçerliliği sinanılabilecek geçici kavramsal bir yapıdır ve özellikle bir olguyu betimleme ve tahmin aşamasında sınama amaçlı olarak kullanılabilir. Aynı olguya yönelik olarak geliştirilen bir model ile bir kuram arasında her zaman keskin bir ayırım yoktur. Modeller bazen yıllarca kuramsal fenerler olarak kalır ve bir alandaki araştırmaya yol gösterirler ve onu yönlendirirler. Ancak bir olgu için bir açıklama geliştirildiğinde bir kuramdan söz edilebilir. Kütüphane ve bilgibilimi alanındaki kuramın çoğu da Bates'e göre aslında modelleme aşamasındadır.

Literatürde kuram tanımları arasında bilim alanları içinde ya da aynı bilim alanı içinde farklılıklar olsa da kuramın rolü konusunda hemen hemen bir görüş birliği vardır. Glaser ve Strauss (1967) kuramın rolünün; (1) açıklama ve bir dereceye kadar davranış tahminini sağlamak, (2) hem araştırmacıların hem de uygulamacıların mümkün olduğu kadar çok durumu anlamalarına ve kontrol etmelerine yardımcı olmak, (3) davranışa bir bakış açısı (perspektif) sağlamak ve (4) araştırmaya rehberlik etmek olduğunu ifade eder.

Alanımızda kuramın önemi ve kuramsal araştırma gereksinimi uzun yıllardır dile getirilmekle birlikte bu alanda kullanılan kuramların neler olduğunu ve kuram kullanımın düzeyini inceleyen az sayıda araştırma vardır. Kütüphane ve bilgi bilimi alanındaki kuram kullanımının yerel boyutu ise incelenmeye muhtaçtır. $\mathrm{Bu}$ araştırmanın temel amacı da Türkiye'de kütüphane ve bilgibilimi alanı araştırmalarının ne ölçüde kurama dayandığını tezlere yansıdığı kadarıyla belirlemektir. Bilindiği gibi tezler ülkemizde yayımlanan çoğu araştırma makalesinin de temel kaynağıdır. Buna göre tezlerde hangi kuramların kullanıldığı; bunların hangi sıklıkla kullanıldıkları, kuram kullanım düzeylerinin derinliği ve kullanılan kuramların bilimsel kökenlerinin ne olduğu belirlenebilecektir. Böylece alanın kuram kullanımındaki yerel durumunu / sorunlarını belirleyecek ve sınırlı da olsa uluslararası bulgular ile karşılaştırma yapmaya olanak verecek bulgular elde edilebilecektir. 


\section{Literatür}

Kütüphane ve bilgibilimi alanındaki kuram kullanımını inceleyen eski ve yeni araştırmalar konuya ilişkin çeşitli analizler sunmaktadır. Järvelin ve Vakkari (1990) kütüphane ve bilgi bilimi alanındaki uluslararası araştırmaların hangi konuları içerdiğini, konuların nasıl bir dağılım gösterdiğini ve bu konuları araştırmak için hangi yaklaşımların ve yöntemlerin kullanıldığını içerik analizi yöntemiyle inceler. Örneklem olarak aldıkları 1985 yılına ait 37 çekirdek dergideki 833 makalenin \%54'ünü araştırma makaleleri oluşturmaktadır. Bu makalelerin ise yalnızca \%10'unda kuram kullanılmıştır. Onlara göre, alan araştırmalarında "temeller ve kavramsal analizler gibi yaygın bilimsel yaklaşımlardan ya da kuramlarla getirilen bilimsel açıklamalardan" pek az yararlanan bir paradigma egemendir (s. 415).

Julien ve Duggan (2000) ise bilgi gereksinimleri ve literatür kullanımına yönelik olarak yaptıkları boylamsal analizde (longitudinal analysis) başka bulgular yanında alanın ne ölçüde kurama dayandığını da araştırmıştır. Buna göre, 1984 - 1989 ve 1995 - 1999 yılları arasında yapılan 300 araştırmanın yalnızca \%18,3'ü kuramsal olarak temellendirilmiş araştırma makalesidir (s. 294).

Pettigrew ve McKechnie (2001) de bilgibilimi araştırmalarında kuram kullanım düzeyini belirlemek için 1993 - 1998 yılları arasında hakemli altı kütüphane ve bilgibilimi dergisinde yayımlanan 1160 makaleyi incelemiş ve 100 farklı kuram adı belirlemişlerdir. Ayrıca, makalelerin \%34'ünde kuram kullanıldığını, kullanılan kuramların çoğunlukla toplumsal bilim kökenli olduğunu (\%45) ve kütüphane ve bilgibilimin ikinci en önemli kuram kaynağı olduğunu (\%30) belirlemişlerdir (s. 67). Bulgular kuram kullanımında bir artış olduğunu gösterse de yazarlar alanda kuram kullanım düzeyinin hâlâ düşük olduğunu ileri sürmüşlerdir. Ayrıca alanda genel olarak kuramın ne olduğu konusunda bir kafa karışıklığı yaşandığını; bunun da farklı araştırma geleneklerinden gelen araştırmacıların kuram kullanımına ilişkin farklı anlayış ve yaklaşımlarından kaynaklandığını ileri sürmüşlerdir. Önceki araştırmalara göre kuram kullanımında belirledikleri artışı da örneklemlerinin görece sık yayımlanan araştırma dergilerini içermesine ve kuram teriminin geniş anlamda kullanılmasına bağlanmışlardır. Çünkü Buckland'ın (1991) da belirttiği gibi alanın tamamı için geçerli ya da alandaki tüm farklı kullanımları kapsayacak tekil bir kuram tanımı yoktur. Buna göre, Pettigrew ve McKechnie (2001) operasyonel bir kuram tanımı geliştirmişlerdir ve makale yazarının "kuram" terimini kullanması -büyük bir hata yoksa- yeterli bulunmuştur.

Jeong ve Kim (2005) 1970 - 1999 tarihleri arasında Güney Kore'de yayımlanmış iki alan dergisinde kuram kullanımını inceleyen içerik analizlerinde 80 farklı kuram adı belirlemişlerdir. Bu analize göre 654 araştırma makalesinin \%20'si kuram adı içermektedir ve bunların çoğunluğu da kütüphane ve bilgibilimi kökenli kuramlardır (\%57,5) (s. 58). Kuramın ne düzeyde uygulandığını da geliştirdikleri en basitten (1) en karmaşığa göre (5) sıralanan beş aşamalı bir model ile analiz eden yazarlar kuramlardan genellikle bir arka plan incelemesi olarak söz edildiğini bulgulamışlardır.

1984 - 2003 yılları arasında yayımlanmış dört alan dergisindeki 1661 makalenin içerik analizini yapan Kim ve Jeong (2006) ise makalelerin \%25,95'inin kuram kullanımına \%41,4'nün ise hem kuram kullanımına hem de geliştirmeye katkı sağladığını bulgulamışlardır. Ayrıca, Vakkari'nin (1998) ve Pettigrew ve McKechnie'nin (2001) daha önce belirttiği gibi bu yazarlar da kuram kullanımının en çok bilgi arama ve kullanma alt konu alanında yoğunlaştığını belirtmişlerdir. Vakkari (1998) bilgi arama davranışı alt alanında kuram kullanımı açısından bir artış yaşandığına işaret etmektedir. Fakat Julien, Pecoskie ve Reed (2011) ile Julien'ın (2014, s. 244) yaptığ 1 görece daha yeni araştırmalara göre bilgi davranışı alt alanında zaman içinde kuram kullanımında çok az bir değişiklik vardır. 
Ocholla ve Roux (2011) kütüphane ve bilgibilimi alanındaki seçili yüksek lisans ve doktora tezlerinin kuramsal çerçevesini içerik analizi yoluyla inceledikleri çalışmada alanın büyük ölçüde diğer disiplinlerden gelen kuramlara dayandığını öne sürer.

2010 - 2014 yılları arasında Kore'de yayımlanan bir alan dergisindeki 344 makaleden oluşan bir örneklemi analiz eden Kim'in $(2015)^{2}$ araştırma sonuçlarına göre ise makalelerin $\% 13,7$ 'sinde kuram kullanılmıştır. Kuram kullanımı çoğunlukla başlangıç düzeyindedir; onu kuram uygulaması düzeyi izlemektedir. Kuramların çoğunluğu da toplumsal bilim (\%58) kökenlidir. Ayrıca, bu çalışmada elde edilen veriler önceki bir araştırmanın 1984 - 2003 arası verileri ile (Kim ve Jeong, 2006) birleştirilerek boylamsal bir analize tabi tutulmuştur. Buna göre kütüphane ve bilgibilimi alanındaki kuramsal araştırmalarda nicel bir artış olmadığ ancak net bir niteliksel büyüme olduğu görülmektedir. Yazarlara göre alandaki araştırmanın kuramsal çerçevesi, toplumsal bilim disiplinleri arasında pedagoji ve psikoloji ile geçmişte olduğundan daha yakın ilişkilere sahiptir.

$\mathrm{Bu}$ kısa literatür değerlendirmesi göstermektedir ki kütüphane ve bilgibilim araştırmalarında \%10 ile \%34 arasında değişen bir kuram kullanım oranı vardır. Bu bulguyu görece bir artış olarak nitelendirmek ise artışın sürekliliğini gösteren bir veri olmadığı için olanaklı değildir. Bununla birlikte kuram konusunun daha fazla önemsendiği ve daha fazla araştırmaya konu olduğu yani niteliksel olarak büyüme gösterdiği ileri sürülebilir. $\mathrm{Bu}$ değerlendirme, alan araştırmacılarının kullandığı ve geliştirdiği pek çok kuram olduğu gibi özellikle toplumsal bilimler alanından kuram ödünç alındığını da göstermektedir. Bilgi arama ise kuramın görece daha fazla kullanıldığı alt alan olarak öne sürülmüştür; fakat görece yeni tarihli son çalışmalar bu alt alandaki kuram kullanımında zaman içinde büyük bir değişim olmadığını göstermektedir.

\section{Yöntem}

Araştırmanın veritabanını YÖK Ulusal Tez Merkezinde listelenen Bilgi ve Belge Yönetimi (BBY) konulu doktora ve yüksek lisans tezleri oluşturmaktadır. Veritabanında Eylül 2019 itibariyle BBY konulu 829 doktora ve yüksek lisans tezi belirlenmiştir; fakat içeriğine erişim izni olan 646 tez bulunmaktadır. 646 tez içinde BBY bölümleri dışında (enformatik, iletişim, işletme, sosyoloji gibi) tamamlanan tezler kapsam dışı bırakıldığında 366 doktora ve yüksek lisans tezine erişilmektedir. Buna göre araştırmanın örneklemini YÖK Ulusal Tez Merkezi Veritabanında listelenen ve $1983-2019^{3}$ yılları arasında BBY bölümlerinde tamamlanmış içeriğine erişim izni olan (gönüllü) 366 doktora ve yüksek lisans tezi oluşturmaktadır $(n=366)$. $\mathrm{Bu}$ örneklem büyüklüğü $+/-0,05$ örnekleme hatası ile belirtilen evren büyüklüğü için \%99 güven düzeyini sağlamaktadır.

Her tez, konusu, içinde geçen kuram ad, kuramın bilimsel kökeni (örneğin, kütüphane ve bilgibilimi, toplumsal bilimler, insan bilimleri, fen bilimleri) ve kuram kullanım düzeyinin derinliği açılarından içerik analizi yöntemiyle incelenmiştir.

İçerik analizi, bir metin türünün ya da görsel işitsel bir materyalin nesnel, sistematik ve niceliksel olarak analizinde kullanılan bir araştırma yöntemidir. Kütüphane ve bilgi bilimi alanında da belirli bir tür araştırma yayınını (kitap, makale, tez vb.) ya da birkaçını birden içerik analizi yöntemiyle inceleyerek, bu yayınlardaki temel araştırma özellikleri yerel, ulusal ya da uluslararası düzeyde incelemek, sıklıkla yapılan bir araştırmadır. İçerik analizi yöntemiyle incelenen bu yapıtlar, alanımızın gelişmişlik düzeyinin ve kuramsal temellerinin bir yansıması olduğu kadar, kütüphanecilerin ya / ya da bilgi yöneticilerinin mesleki

\footnotetext{
${ }^{2}$ Makale Korece'dir. Bilgiler makale özünden alınmıştır.

${ }^{3}$ Eylül 2019
} 
fikirlerinin, önceliklerinin ve uygulamalarının da bir göstergesidir (Rochester, 1995; Meng ve Singh, 2007, s. 398; Kajberg, 1996, s. 25 ve Dilek-Kayaoğlu, 2009, s. 537).

Yukarıda giriş bölümünde verilen kuram tanımlarından da anımsanacağı gibi disiplinlerarası bir alanda kuramın ne olduğuna dair kesin sınırlar çizmek oldukça zordur. $\mathrm{Bu}$ nedenle, bu araştırmada tez yazarının açıklaması kuram kullanımının belirlenmesine temel oluşturmuştur. Örneğin, bir yazar araştırmasında başkasına ait bir kuramın adını anmak ya / ya da nitelemek üzere kuram (ya da teori, model $^{4}$ ya da yasa) terimini kullanmış ise bu kuram olarak bulgulanmıştır. Bu yaklaşım literatürdeki kuram kullanımını en geniş biçimde belirlemek üzere kullanılan bir yaklaşımdır (Pettigrew ve McKechnie, 2001; McKechnie ve Pettigrew, 2002; Jeong ve Kim, 2005). Araştırmanın amacı alanda kullanılan kuramları açıklamak olmadığı gibi kuramın araştırma konusuyla / problemiyle ilişkisinin doğru kurulup kurulmadığı da irdeleme dışı bırakılmıştır.

Kuramların kökeni belirlenirken kuramı ortaya atanın temel araştırma alanı ve yayınları temel alınmış ve şu 4 geniş bilim alanı belirlenmiştir: Kütüphane ve bilgibilimi, toplumsal bilimler, fen bilimleri ve insan bilimleri. Örneğin aslen bir biyolog olan ancak daha çok psikoloji ve bilim kuramı alanında çalışan ve yayın yapmış olan Bertalanffy'ın genel sistemler kuramı toplumsal bilim kökenli kabul edilmiştir. Araştırmada kullanılan her bir tezin konusunu belirlemek üzere ise daha önce geliştirilmiş olan sınıflandırma şemalarından yararlanılmıştır (Järvelin ve Vakkari, 1990; Jeong, 1993). Tablo 1, belirlenen 22 ayrı alt konu alanı göstermektedir. Kuram kullanım düzeyini belirlemek üzere Jeong ve Kim (2005) tarafından geliştirilen "beş derecelik kuram kullanım modeli" (five degrees of theory use) kullanılmıştır. Kuram kullanımının derinliğini değerlendirmeye olanak veren bu modelde önerilen 5 kuram düzeyi (en derinlikli kullanımdan en basit kullanıma doğru) şunlardır: Analitik değerlendirme; kuram uygulaması; kuram tartışması; arkaplan incelemesi ve kuramı anma. Analitik değerlendirme kuramsal temel oluşturmak üzere bir kuramın araştırma boyunca tartışılması / kullanılması anlamına gelir. Kuram uygulamasında ise kuram araştırmanın kavramsal temellerinde yer aldığı gibi araştırmadaki kritik araştırma yöntemlerinden biridir. Kuram tartışması da kuramın derinlemesine bir açıklamasını verir. Arkaplan incelemesi kuramın temel içeriğini birkaç cümle ile açıklar. Kuramı anma ise herhangi bir bibliyografik gönderme yapmadan birkaç sözcükle kuramın adını metinde kullanma olarak açıklanabilir.

\footnotetext{
${ }^{4}$ Kütüphane ve bilgi bilim alanında bazı modeller temel düzey kuram aşamasındadır. Örneğin, Kuhlthau'nun bilgi arama süreci literatürde hem bir model hem de bir kuram olarak geçmektedir. Bu gibi durumlarda model kuram olarak değerlendirilmiştir.
} 
Tablo 1

Alt konu sinıflama şeması

\begin{tabular}{l} 
Genel \\
Meslekler \\
Kütüphane Tarihi \\
Yayımcllı / Çoğaltma Hakkı \\
Kütüphane ve Bilgibilimi Eğitimi \\
Yöntemler ve Yöntembilim \\
Derme Oluşturma ve Geliştirme ya / ya da Derme Yönetimi \\
Bilgi ya da Danışma Hizmetleri \\
Bilgi Kullanıcıları İncelemeleri \\
Kütüphane / Bilgi Merkezi Yönetimi ya / ya da İdaresi \\
Kütüphane ve Bilgi Politikası / Bilgi Ekonomisi / Bilgi Toplumu (Politika) \\
Bilgi Ağı / İşbirliği / Bilimsel İletişim \\
Kataloglama ve Sınıflama \\
Öz Verme ve Dizinleme \\
Bilgi Sistemleri ya / ya da Teknoloji Veritabanı \\
Bilgi Erişim / Bilgi Arama Süreci / Değerlendirme \\
Küttüphane Otomasyonu / Sayısal Kütüphane \\
İnternet Bilgi Kayanakları / Multimedia \\
Bibliyometri \\
Arşiv Materyalleri \\
Diğer Materyaller \\
Diğer Konular (Belge yönetimi ve arşivler için kullanıldı) \\
\hline *Järvelin ve Vakkari, 1990; Jeong, 1993; Jeong ve Kim, 2005.
\end{tabular}

*Järvelin ve Vakkari, 1990; Jeong, 1993; Jeong ve Kim, 2005.

$\mathrm{Bu}$ araştırmada da ilk aşamada tezlerdeki kuram kullanımının varlığ Bunu gerçekleştirmek üzere PDF formatımda kaydedilmiş olan her bir tez iki yüksek lisans öğrencisi tarafından optik karakter tanıma (OCR) yazılımı kullanılarak taranmıştır. Kuram kullanımı belirlenen tezler bizzat yazar tarafindan konu, kuram adı, kuramın kökeni ve düzeyi açılarından içerik analizine tabi tutulmuştur. Birden fazla konuya sahip tezler için ağırlıklı konu temel alınmıştır. Kullanılan her kuram ayrı ayrı sayılıp listelenirken kuram düzeyi kategori başına sadece bir kez sayılmıştır. Elde edilen veriler SPSS programının 16.0 sürümü kullanılarak bir istatistikçinin desteği ile yazar tarafından kodlanmış ve analiz edilmiştir. Veriler tablolar ve yüzdeler kullanılarak tablolaştırılmıştır. Kategorik değerlerin karşılaştırılmasında ki-kare testi kullanılmıştır. Ayrıca iki değişken arasındaki ilişkiyi kurmak için Pearson korelasyon testi kullanılmış ve $p \leq 0.05$ anlamlı kabul edilmiştir (p: anlamlılık düzeyi).

\section{Bulgular}

\section{Temel karakteristikler}

Tablo 2 ve Tablo 3 analiz edilen tezlerin temel özelliklerini vermektedir. Tablo 2 araştırmaya konu olan tezlerin üniversitelerin bilgi ve belge yönetimi bölümlerine göre sayısal ve yüzdesel dağglımını tez türü ayrımı yaparak verirken Tablo 3 içinde kuram adı geçen tezleri yine sayısal ve yüzdesel olarak listelemektedir. Buna göre incelenen tezlerin \%30'u Hacettepe Üniversitesi BBY Bölümünde tamamlanan tezlerdir. Onu sirasıyla İstanbul Üniversitesi (\%23), Ankara Üniversitesi (\%22) ve Marmara Üniversitesi (\%21) izlemektedir. İncelenen tezlerin \%74'ü yüksek lisans tezi \%22'si ise doktora tezidir. Yüksek lisans tezlerinin \%20'si Hacettepe Üniversitesi, \%18'i Marmara Üniversitesi \%16's1 da Ankara ve İstanbul Üniversiteleri BBY bölümlerinde yapılmıştır. Hacettepe Üniversitesi BBY Bölümü en fazla doktora yapılan üniversitedir (\%10); onu İstanbul Üniversitesi (\%7) ve Ankara Üniversitesi (\%6) BBY Bölümleri izlemektedir (Tablo 2). 
Tablo 2

Üniversitelere Göre Tamamlanan Tezler ( $n=366)$

\begin{tabular}{lrrrrrr}
\hline & \multicolumn{2}{c}{ Yüksek lisans tezi } & \multicolumn{2}{c}{ Doktora tezi } & \multicolumn{2}{c}{ Toplam } \\
\cline { 2 - 7 } Üniversite & $\mathrm{n}$ & $\%$ & $\mathrm{n}$ & $\%$ & $\mathrm{n}$ & $\%$ \\
\hline Ankara Üniversitesi BBY Bölümü & 59 & 16,1 & 21 & 5,7 & 80 & 21,9 \\
Atatürk Üniversitesi BBY Bölümü & 7 & 1,9 & 1 & 0,3 & 8 & 2,2 \\
Çankırı Üniversitesi BBY Bölümü & 6 & 1,6 & 0 & 0,0 & 6 & 1,6 \\
Hacettepe Üniversitesi BBY Bölümü & 74 & 20,2 & 37 & 10,1 & 111 & 30,3 \\
İstanbul Üniversitesi BBY Bölümü & 59 & 16,1 & 24 & 6,6 & 83 & 22,7 \\
Marmara Üniversitesi BBY Bölümü & 65 & 17,8 & 13 & 3,6 & 78 & 21,3 \\
Toplam & 270 & 73,8 & 96 & 26,2 & 366 & 100,0 \\
\hline
\end{tabular}

Tablo 3 ise tezlerin \%22'sinde en az bir kuram adi geçtiğini göstermektedir. İçinde kuram adı geçen tezlerin \%17'si yüksek lisans tezi iken \%37'si doktora tezidir. Ki-kare testi tez türü ile kuram kullanımı (var / yok) arasında istatistiksel olarak anlamlı bir ilişki olduğunu göstermektedir $\left(\chi^{2}(1)=14,785 ; p<0,001\right)$. Doktora tezlerinde yüksek lisans tezlerine göre daha fazla kuram kullanılmaktadır. Kuram kullanımı ile (var / yok anlamında) üniversite BBY bölümleri arasında ise istatistiksel olarak anlamlı bir ilişki bulunamamıştır.

Tablo 3

Tez Türüne Göre Kuram Kullanımı

\begin{tabular}{lrrrrrr}
\hline & \multicolumn{3}{c}{ Kuram kullanımı var } & Kuram kullanım yok & \multicolumn{2}{c}{ Toplam } \\
\cline { 2 - 7 } Tez türü & $\mathrm{n}$ & $\%$ & $\mathrm{n}$ & $\%$ & $\mathrm{n}$ & $\%$ \\
\hline Yüksek lisans & 47 & 17,4 & 223 & 82,6 & 270 & 100 \\
Doktora & 35 & 36,5 & 61 & 63,5 & 96 & 100 \\
Toplam & 82 & 22,4 & 284 & 77,6 & 366 & 100 \\
\hline
\end{tabular}

Kuram adı geçen tezlerin konuları da yüzdelik dilimler halinde tablolaştırılmıştır (Tablo 4). Buna göre en fazla kuram kullanımı \%18 ile kullanıcı incelemeleri alt konu alanındaki tezlerde görülmektedir. Onu \%16 ile kütüphane / bilgi merkezi yönetimi / ya da idaresi ve belge yönetimi alanı ve $\% 9$ ile bilgi sistemleri ya / ya da teknoloji / veritabanı alt konu alanı izlemektedir.

Tablo 4

Konularına Göre Kuram Kullanımı

\begin{tabular}{lrr}
\hline & \multicolumn{2}{c}{ Kuram kullanılan tezler } \\
\cline { 2 - 3 } Alt konular & $\mathrm{n}$ & $\%$ \\
\hline Genel & 6 & 7,3 \\
Meslekler & 5 & 6,1 \\
Yayı̈ıılık / Çoğaltma Hakkı & 3 & 3,7 \\
Kütüphane ve Bilgibilimi Eğitimi & 1 & 1,2 \\
Derme Oluşturma ve Geliştirme ya / ya da Derme Yönetimi & 2 & 2,4 \\
Bilgi Kullanıcısi İncelemeleri & 15 & 18,3 \\
Kütüphane / Bilgi Merkezi Yönetimi / ya da İdaresi & 13 & 15,9 \\
Kütüphane ve Bilgi Politikası / Bilgi Ekonomisi / Bilgi Toplumu (Politika) & 3,7 \\
Kataloglama ve Sinıflama & 3 & 1,2 \\
Bilgi Sistemleri ya / ya da Teknoloji / Veritabanı & 1 & 9,8 \\
Bilgi Erişim / Bilgi Arama Süreci / Değerlendirme & 8 & 6,1 \\
Bibliyometri & 5 & 7,3 \\
Diğer Materyaller & 6 & 1,2 \\
Diğer (Belge Yönetimi) & 1 & 15,9 \\
Toplam & 13 & 100,0 \\
\hline
\end{tabular}


Tablo 5

Kuram Kullanım Siklı̆̆l, Kuram Kullanım Düzeyi ve Kuramın Kökeni

\begin{tabular}{lrrr}
\hline Kuram adı & Kullanım sıklığ & Kullanım düzeyi & Köken \\
\hline Bertalanffy'ın Genel Sistemler Kuramı & 12 & 1,83 & TB \\
Wilson'ın Bilgi Arama Davranışı Kuramı (1981 ve 1999) & 12 & 3 & KB \\
Belge Yaşam Döngüsü Kuramı & 12 & 2,09 & KB \\
F. W. Taylor'ın Bilimsel Yönetim Kuramı & 10 & 2,60 & TB \\
Kuhlthau'nun Bilgi Arama Süreci & 10 & 3 & KB \\
Ellis'ın Bilgi Arama Kuramı & 9 & 3 & KB \\
Krikelas'ın Bilgi Arama Davranışı & 8 & 3 & KB \\
Dervin'in Anlamlandırma Kuramı & 8 & 3 & TB \\
Maslow'un A. Gereksinimler Hiyerarşisi Kuramı & 7 & 2,7 & TB \\
Deming'in Toplam Kalite Yönetimi Kuramı & 7 & 2,5 & TB \\
Shannon and Weaver'ın Mathematiksel İletişim Kuramı & 6 & 1,2 & FB \\
Fayol'un Örgüt Kuramı & 6 & 2,3 & TB \\
Weber'in Bürokrasi Kuramı & 6 & 2,1 & TB \\
Provenans İlkesi (Asli Düzene Saygı İlkesi ile) & 6 & 1,8 & KB \\
Öğrenme Kuramı & 6 & 1,3 & TB \\
McClelland'ın Başarma İhtiyacı Kuramı & 5 & 3,0 & TB \\
Vroom'un Beklenti Kuramı & 5 & 2,8 & TB \\
Price Yasası & 5 & 2,8 & KB \\
Belkin'in Bilgi (Knowledge) Anomalisi Durumu (ASK) & 5 & 2,8 & KB \\
\hline
\end{tabular}

*FB: Fen Bilimleri; KB: Kütüphane ve Bilgibilimi; TB: Toplumsal Bilimler.

\section{Kuram adlarl ve kuram kullanım sikliğ}

Yapılan içerik analizi sonucunda tezlerde kullanılan 75 kuram adı belirlenmiştir. Belirlenen bu kuramların tam bir listesi makalenin ekinde alfabetik düzende verilmiştir. Tablo 5 ise tezlerde 5 ya da daha fazla sayıda kullanılan 19 kuram adını kullanım sıklığına göre sıralamakta ve bu kuramların kullanım düzeyi ile kökenini vermektedir. Buna göre, Bertalanffy'ın genel sistemler kuramı, Wilson'ın bilgi arama davranışı kuramı (1981 ve 1999) ve belge yaşam döngüsü kuramı en fazla kullanılan kuramlardır. Onları F. W. Taylor'ın bilimsel yönetim kuramı, Kuhlthau'nun bilgi arama süreci, Ellis'ın bilgi arama kuramı, Krikelas'ın bilgi arama davranışı kuramı ve Dervin'in anlamlandırma kuramı izlemektedir.

\section{Kuram kullanım düzeyi}

Bertalanffy'ın genel sistemler kuramı en sık kullanılan kuram olmasına karşın kuram kullanım düzeyi açısından oldukça düşük bir ortalamaya sahiptir $(1,83)$. Yöntem bölümünden anımsanacağı gibi tez kullanım derinliğini değerlendirmek üzere 5 kuram düzeyi (en derinlikli kullanımdan en basit kullanıma doğru) belirlenmişti. Buna göre 5 üzerinden 1,83 kuram kullanım ortalamasına sahip olan Bertalanffy'ın genel sistemler kuramı anma (düzey 1) ve arkaplan incelemesi (düzey 2) düzeyi arasında kullanılmıştır. Buna karşın kütüphane ve bilgibilim alanındaki kuramların görece daha yüksek bir kullanım düzeyi ortalaması vardır. Örneğin Wilson'ın bilgi arama davranışı kuramı (1981 ve 1999), Kuhlthau'nun bilgi arama süreci, Krikelas'ın bilgi arama davranışı, Ellis'ın bilgi arama kuramı, Dervin'in anlamlandırma kuramı tezlerde daha kapsamlı biçimde ele alınmış; kuram tartışması yapılarak derinlemesine bir açıklama verilmiştir (düzey 3). Tablo 5 kullanım sıklığına bağlı olarak düzenlendiği için kuram kullanım düzeyleri yüksek tezleri göstermemektedir; fakat 4 ortalama ile Bradford dağılım yasası, Zipf yasası (en az çaba kuramı), birleştirilmiş teknoloji kabul ve kullanım kuramları kuram kullanım düzeyi en yüksek kuramlar olarak burada ayrıca anılmalıdır. Tezlerdeki kuram kullanım düzeyinin genel ortalaması ise 2,6'dır. 
Tablo 6

Kuramın Bilimsel Kökenine Göre Kullanım Siklı̆ğ

\begin{tabular}{lr}
\hline Köken & $\mathrm{n}$ \\
\hline Toplumsal Bilimler & 131 \\
Kütüphane ve bilgibilimi & 91 \\
Fen Bilimleri & 19 \\
İnsan Bilimleri & 5 \\
\hline
\end{tabular}

\section{Kuramın bilimsel kökeni}

Tezlerde kullanılan kuramların büyük çoğunluğu toplumsal bilim kökenlidir $(\% 58,67)$; ardından da sirasıyla kütüphane ve bilgibilim $(\% 30,67)$, fen bilimleri $(\% 8)$ ve insan bilimleri $(\% 2,67)$ kökenli kuramlar gelmektedir (Ek 1). Toplumsal bilim kökenli kuramların çoğu da psikoloji ve yönetim disiplinlerine aittir. Kullanım sıklığı beş ve daha fazla olan kuramların kökenine bakıldığında da çoğunluğunun toplumsal bilimlere ait olduğu görülmektedir. Tablo 6 tezlerin kökenine göre kullanım sıklığını göstermektedir. Buna göre toplumsal bilimler kökenli kuramlar $131 \mathrm{kez}$ kullanılırken kütüphane ve bilgibilim kökenli kuramlar $91 \mathrm{kez}$, fen bilimleri kökenli kuramlar 19 kez ve insan bilimleri kökenli kuramlar beş kez kullanılmıştır.

\section{Değerlendirme ve Sonuç}

Kuram terimi, Türkçe'de birleştirmek, oluşturmak, yapmak yanında hayal kurmak ve düşünmek anlamlarına da gelen kurmak eyleminden gelir ve teori ile eşanlamlı olarak kullanılır. Teori terimi ise Grekçe Theoria'dan gelir. Theoria seyre dalmak, görmek ya da görünür hale getirmek anlamında theatre (tiyatro) terimi ile aynı köktendir. Bilimsel kuram ise olguları ve olgular arasındaki ilişkileri betimleyen, onları sistemli bir biçimde açıklamaya çalışan ve tahminler getiren genellemeler ve ilkeler bütünüdür. Kuşkusuz, kuram yalnızca incelenen olayın / davranışın / olgunun ve olgular arasındaki ilişkilerin ne olduğuna değil aynı zamanda "neden" olduğuna ilişkin mantıksal bir çerçeve sağlar. Sınamalara açılan her yeni kuram da çeşitli denetlemelere tabi tutulur. Öte yandan kuramlar araştırılmaya değer olgu ve olgusal ilişkileri betimlendiğinden, yeni araştırma sorularının oluşturulmasına da olanak verirler; böylece daha sonra yapılacak araştırmalar için de yol gösterilmiş olur. Ayrıca, bir alanda yeni bir kuram geliştirmek için eskilerini de iyi bilmek gereklidir.

Birçok araştırmacı kütüphane ve bilgibilimi alanını yeni kuram oluşturma ya da var olan kuramları geliştirme ve kullanma konusunda yeterli bulmamaktadır. Oysa bir disiplinin bilim iddiası geliştirdiği kuramlar üzerinden olmaktadır. Kütüphane ve bilgibilimi alanının iyi kuramlardan yoksun olması ya da bilimsel yaklaşım ve açıklamalardan yeterince yararlanmayan / "kuramsal olmayan" yapısı mesleki bir uygulama olarak ortaya çıkışıyla ilişkilendirilir çoğunlukla. Çünkü alan için uygulama sorunları ve teknik eğitim modeli hep öncelikli olmuştur.

Literatür değerlendirmesi göstermektedir ki kütüphane ve bilgibilim araştırmalarında $\% 10$ - \%34 arasında değişen bir kuram kullanım oranı vardır. Bu bulguyu görece bir artış olarak nitelendirmek ise, artışın sürekliliğini gösteren bir veri olmadığı için olanaklı değildir. Bununla birlikte kuram konusunun daha fazla önemsendiği ve daha fazla araştırmaya konu olduğu, yani niteliksel olarak büyüme gösterdiği ileri sürülebilir. Ayrıca alan araştırmacılarının kullandığı ve geliştirdiği pek çok kuram olduğu gibi alanda kullanılan birçok kuramın kökeni toplumsal bilimlerdir. Bilgi arama ise kuramın görece daha fazla kullanıldığ 1 alt alan olarak öne sürülmüştür; fakat görece yeni tarihli son çalışmalar bu alt alandaki kuram kullanımında zaman içinde büyük bir değişim olmadığını göstermektedir.

$\mathrm{Bu}$ araştırmanın bulguları genel olarak kütüphane ve bilgibilimin evrensel düzeydeki kuramsal sorunlarının yerel düzeyde de yaşandığı göstermektedir. Yapılan içerik analizinde 1983 - 2019 yılları arasında Türkiye'de kütüphane ve bilgibilim alanında yapılmış ve erişim 
izni olan 366 lisansüstü tezin \%22'sinde kuram kullanımı belirlenmiştir. Elde edilen bu oranın düşük olmakla birlikte alan literatüründe elde edilen (araştırma makalelerinin içerik analiziyle elde edilen \%10 - \%34 arasındaki kuram kullanımı) bulgularla genel olarak paralellik gösterdiği söylenebilir; ancak tezlerin kuramsal çerçevesinin daha yüksek oranda kuramlarla desteklenmiş olmasının bekleneceği de burada dile getirilmelidir. Çünkü kuram bir tezin kuramsal çerçevesinin önemli bir parçasıdır ve genellikle tezlerin literatür tartışması bölümünde ya da ayrı bir bölüm olarak yer alırlar. Böylece tez konusuna açıklama getiren kuram ya da kuramlar tartışılır / tartışılmalıdır. \%22'lik bir kuram kullanımı ise tezlerin kuramsal çerçevesinin uygun bir kuram ile ilişkilendirilmesinde bir zayıflık olduğunu göstermektedir. Bununla birlikte içinde kuram adı geçen tezlerin \%17'si yüksek lisans tezi iken \%36'sı doktora tezidir. Ki-kare testi tez türü ile kuram kullanımı (var / yok) arasında istatistiksel olarak anlamlı bir ilişki olduğunu göstermektedir $\left(\left(\chi^{2}(1)=14,785 ; p<0.001\right)\right.$. Yeni bilgi üretme amacı olan doktora tezlerinde yüksek lisans tezlerine göre daha fazla kuram kullanılması, doktora tezleri için doğal bir sonuç olarak değerlendirilebilir.

En fazla kuram kullanımı \%18 ile kullanıcı incelemeleri alt konu alanındaki tezlerde görülmektedir. Onu \%16 ile kütüphane / bilgi merkezi yönetimi alt konu alanı izlemektedir. Bertalanffy'ın genel sistemler kuramı, Wilson'ın bilgi arama davranışı kuramı ve belge yaşam döngüsü kuramı tezlerde 5 ya da daha fazla sayıda kullanılan kuramlardır. Onları F. W. Taylor'ın bilimsel yönetim kuramı, Kuhlthau'nun bilgi arama süreci, Ellis'ın bilgi arama kuramı, Krikelas'ın bilgi arama davranışı kuramı ve Dervin'in anlamlandırma kuramı izlemektedir. Kütüphaneyi / bilgi merkezini bir sistem olarak değerlendirmek üzere kuramsal bir perspektif sunan Bertalanffy'ın genel sistemler kuramı en sık kullanılan kuram olmasına karşın 5'li kuram kullanım düzeyi modeline göre düşük bir ortalamaya sahiptir $(1,83)$ ve daha çok arkaplan incelemesi derinliğinde ele alınmıştır. Buna karşın Wilson'ın bilgi arama davranışı kuramı, Kuhlthau'nun bilgi arama süreci, Krikelas'ın bilgi arama davranışı, Ellis'ın bilgi arama kuramı, Dervin'in anlamlandırma kuramı tezlerde daha derinlikli biçimde ele alınmış kütüphane ve bilgibilim kökenli kuramlardır ve kuram tartışması düzeyinde kullanılmışlardır. Bradford dağılım yasası, Zipf yasası (en az çaba kuramı) gibi bibliyometrik kuramlar ile birleştirilmiş teknoloji kabul ve kullanım kuramı kullanım düzeyi en yüksek kuramlardır (kuram uygulaması düzeyi). Tezlerdeki kuram kullanım düzeyinin genel ortalaması ise 2,6'dır. Ayrıca, tezlerde 75 ayrı kuramın kullanıldığ belirlenmiştir ve bunların büyük çoğunluğu, Pierce (1992) ve Pettigrew ve McKechnie'nin (2001) de belirlediği gibi, toplumsal bilim kökenlidir $(\% 58,6)$; ardından da kütüphane ve bilgibilim $(\% 30,6)$ tezleri gelmektedir. Ayrıca, literatür değerlendirmeden anımsanacağı gibi yaptıkları içerik analizi sonucunda Pettigrew ve McKechnie (2001) 100 farklı kuram, Jeong ve Kim (2005) ise 80 farklı kuram adı belirlemişlerdi. Buna göre, Türkiye'de kütüphane ve bilgibilim alanındaki araştırmalarda hem değişik toplumsal bilimlerden kuram ödünç alındığı hem de alanın kendine özgü kuramlarından yararlanıldığı görülmektedir; toplumsal bilimler arasında ise özellikle psikoloji ve yönetim disiplinleri alanda kullanılan birçok kuramın kaynağıdır.

$\mathrm{Bu}$ araştırmada elde edilen bulgular Türkiye'de kütüphane ve bilgibilimi araştırmalarında kuram kullanımını anlamaya yönelik ilk adımı temsil etmektedir ve bazı sınırlılıklara sahiptir. Örneğin, erişim izni verilmeyen tezler bu araştırmanın kapsamı dışında kalmıştır. $\mathrm{Bu}$ durum bir sınırlılık olarak değerlendirilebilir. Fakat asıl sınırlılık, alan araştırmasının tamamına yönelik bir veri olmamasıdır ve bu nedenle genel bir yargıya varmak oldukça zordur. Tezler Türkiye'de kütüphane ve bilgibilimi alanında yayımlanan çoğu araştırma makalesinin temel kaynağı da olsa, yapılması planlanan araştırma makalelerine yönelik bir içerik analizi kuram kullanımına yönelik tablonun tamamını görmeyi sağlayacaktır. Türkiye'de kütüphane ve bilgi bilimi alanında yüksek bir toplumsal kurumsallaşma sağlanmıştır. Üniversite düzeyinde örgütlenen araştırmaya dayalı akademik bir ortam, mesleki yayınlar ve lisans ve lisansüstü düzeyde yetişmiş profesyonel bir çevre vardır. 
$\mathrm{Bu}$ türden kuramsal araştırmalar da alanın yerel ve evrensel düzeyde bilişsel kurumsallık düzeyini / entelektüel kimliğini geliştirme / yükseltme sürecine önemli katkılar sağlayacaktır

\section{Teşekkür}

Veri toplama sürecine katkı sağlayan yüksek lisans öğrencilerim sevgili Gülsemin Çoşkun’a ve Jülide Burçin Subaşı'na özenli ve özverili çalışmaları için çok teşekkür ederim.

\section{Kaynakça}

Bates, M. (2009). An introduction to metatheories, theories, and models. Library and Information Science, 11(44), 275-297.

Brookes, B.C. (1980). The foundations of information science. Part I: Philosophical aspects. Journal of Information Science, 2, 125-133.

Buckland, M. (1991). Information and information systems. Westport, CN: Greenwood.

Buckland, M. (1999). Library services in theory and context. 2nd. ed. Erişim adresi: https://digitalassets.lib.berkeley.edu/sunsite/Library\%20Services\%20in\%20Theory\%20and\%20 Context,\%202nd\%20Edition.pdf

Butler, P. (1933). Introduction to library science. Chicago: Chicago University Press.

Dilek-Kayaoğlu, H. (2009). İstanbul Üniversitesi Bilgi ve Belge Yönetimi Bölümü’nde araştırma eğilimleri 1967-2008: Lisansüstü tezlerinin içerik analizi. Türk Kütüphaneciliği, 23, 535-562.

Dilek-Kayaoğlu, H. (2017). Kütüphane biliminden enformasyon bilimlerine: İnceleme alanını / bilim dalını adlandırma ve tanımlanma sorunu. B. Yılmaz, T. Baş, S. Öztemiz ve M. Dişli (Ed.). Bilgi ve belge yönetimi: Kuramsal yaklaşımlar (s. 64-123) içinde. İstanbul: Hiperlink.

Glaser, B. G. ve Strauss, A. L. (1967). The discovery of grounded theory: Strategies for qualitative research. Chicago: Aldine Publishing.

Glazier, J.D. ve Grover, R. (2002). A multidisciplinary framework for theory building. Library Trends, 50(3), 317-329.

Grover, R. ve Glazier, J.D. (1986). A conceptual framework for theory building in library and information science. Library and Information Science Research, 8, 227-242.

Güncel Türkçe Sözlük. Erişim adresi: https://sozluk.gov.tr/

Hauser, L. (1988). A conceptual analysis of information science. Library and Information Science Research, 10, 3-34.

Hjørland, B. (1998). Theory and metatheory of information science: A new interpretation. Journal of Documentation, 54(5), 606-621.

Järvelin, K. ve Vakkari, P. (1990). Content analysis of research articles in library and information science. Library and Information Science Research, 12(4), 395-421

Jeong, D. Y. (1993). Theory building in library and information science based on research method analysis. Journal of the Korean Society for Information Management, 10(2), 23-41.

Jeong, D. Y. ve Kim, S. J. (2005). Knowledge structure of library and information science in South Korea. Library and Information Science Research, 27, 51-72.

Julien, H. (2014). Information behavior research: Where have we been, where are we going? Canadian Journal of Information and Library Science, 38(4), 239-250.

Julien, H. ve Duggan, L. J. (2000). A longitudinal analysis of the information needs and uses literature. Library and Information Science Research, 22, 1-19.

Julien, H., Pecoskie, JJL. ve Reed, K. (2011). Trends in information behavior research, 1999- 2008: A content analysis. Library and Information Science Research, 33(1), 19-24.

Kajberg, L. (1996). A content analysis of LIS serial literature published in Denmark 1957-1986. Library and Information Science Research, 18, 25-52. 
Keseroğlu, H. S. (2010). Bilginin bilgisi: Kütüphane ve bilgibilim kuramı sorunsalı. Türk Kütüphaneciliği, 24, 685-704.

Kim, S. J. (2015). An analysis of research trends on theory use in Korean library and information science: Focusing on journal of the Korean Society for Library and Information Science from 2010 through 2014. Journal of the Korean BIBLIA Society for Library and Information Science, 26(4), 179-200.

Kim, S. J. ve Jeong, D. Y. (2006). An analysis of the development and use of theory in library and information science research articles. Library and Information Science Research, 28(4), 54862.

McKechnie, L. E. F. ve Pettigrew, K. (2002). Surveying the use of theory in library and information science research: A disciplinary perspective. Library Trends, 50(3), 406-17.

Meng, G. F ve Singh, D. (2007). Trends in Malaysian LIS research 1996-2006: A content analysis of the MJLIS articles. Abrizah Abdullah, et al. (Eds.) ICOLIS, International Conference on Libraries, Information and Society, ICoLIS 2007, Malaysia, 26-27 June 2007 (397-406), içinde. Kuala Lumpur: LISU, FCSIT.

Ocholla, D. ve Roux, C. L. (2011). Conceptions and misconceptions of theoretical frameworks in library and information science research: A case study of selected theses and dissertations from eastern and southern African universities. Mousaion, 29(2), 61-74.

Pettigrew, K. ve McKechnie, L. E. F. (2001). The use of theory in information science research Journal of The American Society for Information Science and Technology, 52(1), 62-73.

Pierce, S. J. (1992). Dead Germans and the theory of librarianship. American Libraries, September, 641-643.

Rochester, M. (1995). Library and information science research in Australia 1985-1994: a content analysis of research articles in The Australian Library Journal and Australian Academic and Research Libraries. Australian Academic and Research Libraries, 26(3),163-170.

Vakkari, P. (1998), "Growth of theories on information seeking: an analysis of growth of a theoretical research program on the relation between task complexity and information seeking", Information Processing \& Management, 34(2/3), 361-82.

Van Maanen, J. (1998). Different strokes: Qualitative research in the administrative science quarterly from 1956 to 1996. J. Van Maanen (Ed.), Qualitative studies of organizations (ix-xxxii) içinde. Thousand Oaks, CA: Sage.

Yıldırım, C. (1985). Bilim felsefesi. İstanbul: Remzi.

Yılmaz, B. (2017). Önsöz. B. Yılmaz, T. Baş, S. Öztemiz ve M. Dişli (Ed.). Bilgi ve belge yönetimi: Kuramsal yaklaşımlar (s. 8-11) içinde. İstanbul: Hiperlink.

Yontar, A. (2004). Türkiye'de kütüphane ve enformasyon bilimi teorisi: Temel sorunlar. S. Arslantekin ve F. Özdemirci (Ed.). Kütüphaneciliğin Destanı: Uluslararası Sempozyumu: 2124 Ekim 2004, Ankara (Bildiriler) (14-30) içinde. Ankara: Ankara Üniversitesi Dil ve TarihCoğrafya Fakültesi Bilgi ve Belge Yönetimi Bölümü. 
Ek 1. Kuram ad ve kökenleri

\begin{tabular}{|c|c|}
\hline Kuram Adları & Kökeni \\
\hline Adams'ın Eşitlik Kuramı & Toplumsal Bilimler \\
\hline Fishbein ve Ajzen'nin ${ }^{5}$ Gerekçeli Eylem Kuramı & Toplumsal Bilimler \\
\hline Alderfer ERG Kuramı & Toplumsal Bilimler \\
\hline Alvin Toffler'in Üç Dalga Kuramı & Toplumsal Bilimler \\
\hline Arşivsel Kuram & Kütüphane ve Bilgibilim \\
\hline Bandura’nın Sosyal Öğrenme Kuramı & Toplumsal Bilimler \\
\hline (Belge) Yaşam Döngüsü Kuramı & Kütüphane ve Bilgibilim \\
\hline Belkin'in Bilgi Anomalisi Durumu (ASK) & Kütüphane ve Bilgibilim \\
\hline Bertalanffy'ın Genel Sistemler Kuramı & Toplumsal Bilimler \\
\hline Birleştirilmiş Teknoloji Kabul ve Kullanım Kuramı & Toplumsal Bilimler \\
\hline Bradford Dağı̆ım Yasası & Kütüphane ve Bilgibilim \\
\hline Brookes'un Enformasyon Bilimi Denklemi & Kütüphane ve Bilgibilim \\
\hline Burton ve Kebler'ın Yarı Yaşam Kuramı & Kütüphane ve Bilgibilim \\
\hline Chatman’ın Bilgi Yoksulluğu Kuramı & Toplumsal Bilimler \\
\hline Codd'ın İlişkisel Modeli & Fen Bilimleri \\
\hline Çizge Kuramı & Fen Bilimleri \\
\hline Çoklu Zeka Kuramı & Toplumsal Bilimler \\
\hline Davis'in Teknoloji Kabul Kuramı & Toplumsal Bilimler \\
\hline Değişim Kuramları & Toplumsal Bilimler \\
\hline Deming'in Toplam Kalite Yönetimi Kuramı & Toplumsal Bilimler \\
\hline Dervin'in Anlamlandırma Modeli & Toplumsal Bilimler \\
\hline Ellis'ın Bilgi Arama Kuramı & Kütüphane ve Bilgibilim \\
\hline Fayol'ın Örgüt Kuramı & Toplumsal Bilimler \\
\hline Feminist Kuram & Toplumsal Bilimler \\
\hline Fikri Mülkiyet Kuramı & Toplumsal Bilimler \\
\hline Freud'un Psiko-analitik Gelişim Kuramı & Toplumsal Bilimler \\
\hline Garfield'ın Bibliyografik Yoğunlaşma Yasası & Kütüphane ve Bilgibilim \\
\hline Glasser'in Kontrol Kuramı & Toplumsal Bilimler \\
\hline Grönroos'un Hizmet Kalitesi Modeli & Toplumsal Bilimler \\
\hline Herzberg'in Motivasyon-Hijyen Kuramı & Toplumsal Bilimler \\
\hline Holland'ın Kişilik Kuramı & Toplumsal Bilimler \\
\hline Ingwersen Bilgi Arama Kuramı & Kütüphane ve Bilgibilim \\
\hline Ingwersen ve Järvelin Bilgi Arama ve Erișim & Kütüphane ve Bilgibilim \\
\hline Kelly’nin Kişisel Yapı Kuramı & Toplumsal Bilimler \\
\hline Kleinrock'in Paket Anahtarlama Kuramı & Fen Bilimleri \\
\hline Kohlberg'in Ahlak Kuramı & Toplumsal Bilimler \\
\hline Krikelas'ın Bilgi Arama Davranışı Kuramı & Kütüphane ve Bilgibilim \\
\hline Kuhlthau’un Bilgi Arama Süreci Kuramı & Kütüphane ve Bilgibilim \\
\hline Leckie, Pettigrew ve Sylvain'ın Mesleki Bilgi Arama Davranışı Modeli & Kütüphane ve Bilgibilim \\
\hline Locke’un Tutarsızlık Kuramı & Toplumsal Bilimler \\
\hline Lotka Yasası & Kütüphane ve Bilgibilim \\
\hline Marchionini’nin Bilgi Arama Süreci Modeli & Kütüphane ve Bilgibilim \\
\hline Marksist Kuram & Toplumsal Bilimler \\
\hline Maron ve Kuhn’un İlgililik Kuramı & Kütüphane ve Bilgibilim \\
\hline Marshall Mcluhan Teknolojik Gereklilik Kuramı & Toplumsal Bilimler \\
\hline Maslow’un Gereksinimler Hiyerarşisi Kuramı & Toplumsal Bilimler \\
\hline McClelland'ın Başarma İhtiyacı Kuramı & Toplumsal Bilimler \\
\hline McGregor'ın Kuram X Kuram Y’si & Toplumsal Bilimler \\
\hline Mellon’ın Kütüphane Kaygısı Kuramı & Kütüphane ve Bilgibilim \\
\hline Neumann ve Morgenstern'ın Oyun Kuramı & Toplumsal Bilimler \\
\hline Nonaka ve Takeuchi'nin Örgütsel Bilgi Yaratma Kuramı & Toplumsal Bilimler \\
\hline Öğrenme Kuramı ${ }^{6}$ & Toplumsal Bilimler \\
\hline Pareto Yasası (80/20 İlkesi) & Toplumsal Bilimler \\
\hline
\end{tabular}

${ }^{5}$ Fishbein'ın eklenmediği örnekler de vardır.

${ }^{6}$ Bilişsel, toplumsal, istatistiksel. 
Piaget'nin Bilişsel Gelişim Kuramı

Ajzen'in Planlı Davranış Kuramı

Price Yasas1

Provenans İlkesi (asli düzene saygıyı da içeriyor)

Reddin'in Z Kuramı

Rocchio ve Salton'ın Vektör Uzayı Modeli

Roe'nun İhtiyaç Kuramı

Roger'ın Yeniliğin Yayılması Kuramı

Saracevic'in Bilgi Erişim Modeli

Shannon ve Weaver'1n Matematiksel İletişim Kuramı

Spearman'ın İki Faktör Kuramı

Spink'in Bilgi Erişim Modeli

Taylor'ın Bilimsel Yönetim Kuramı

Thorndike'ın Çok Faktör Kuramı

Toury'nin Erek Odaklı Çeviri Kuramı

Urquhart Yasası

Vroom'um Beklenti Kuramı

Vygotsky'in Potansiyel Gelișim Alanı Kuramı

Weber'in Bürokrasi Kuramı

Wilson Bilgi Arama Davranış1 (1981-1999)

Zadeh'in Bulanık Kümeler Kuramı

Zipf Yasası (En Az Çaba Kuramı)
Toplumsal Bilimler

Toplumsal Bilimler

Kütüphane ve Bilgibilim

Kütüphane ve Bilgibilim

Toplumsal Bilimler

Fen Bilimleri

Toplumsal Bilimler

Toplumsal Bilimler

Kütüphane ve Bilgibilim

Fen Bilimleri (matematik)

Toplumsal Bilimler Kütüphane ve Bilgibilim

Toplumsal Bilimler

Toplumsal Bilimler

İnsan Bilimleri

Kütüphane ve Bilgibilim

Toplumsal Bilimler

Toplumsal Bilimler

Toplumsal Bilimler

Kütüphane ve Bilgibilim

Fen Bilimleri

İnsan Bilimleri 


\section{Summary}

The term "kuram" comes from the act of establishing, which means combining, creating, and making, along with the meanings of dreaming and thinking and is used synonymously with theory, whereas the term theory comes from "theoria" in Greek. Theoria has the same origin as the theater, which means watching, seeing, or making visible. A scientific theory, on the other hand, is a set of generalizations and principles that describe phenomena and their relationships, attempt to explain them systematically, and make predictions. Obviously, the theory provides a logical framework not only on what the events / behaviors / phenomena and the relationships between phenomenon are but also on "why" they occur. Each new theory opened for tests is subject to various controls. On the other hand, since the theories describe the phenomenon and phenomenal relationships which are worthy of investigation, they also allow the production of new research questions. Besides, it is necessary to know the old ones well to develop a new theory in a field.

Many researchers do not find the library and information science field sufficient enough to create new theories or to develop and use existing theories. However, a discipline may claim to be scientific only through the theories it developed. The lack of good theories in the field of library and information science, or it's not using a scientific approach and explanations / non-theoretical structure, is often associated with its emergence as a professional practice because the implementation problems and the technical education model have always been a priority for the field.

The literature review shows that the theory used in library and information science research is ranging between $10 \%$ to $34 \%$. Since no data is showing the continuity of the increase, it is not possible to characterize this finding as an increase. However, it can be argued that the theory is considered much more and is subject to more research, which means that it grows qualitatively. Besides, although there are many theories used and developed by field researchers, many theories used in the field have their origins in social sciences. Information behavior has been suggested as a sub-area where the theory is used relatively more, but recent studies show that there has been no major change in the use of theory in this sub-domain over time.

The findings of this study show that the theoretical problems of library and information science at the universal level are also experienced at the local level. According to content analysis, the use of theory rate in the graduate thesis in the field of library and information science is $22 \%$ between the years 1983 - 2019, in Turkey. Although this ratio is low (a rate of $10-34 \%$ for the use of theory, obtained by content analysis of research articles), it can be said that it is close to the findings of the field literature. Yet, it should be stated here that the theoretical framework of the theses is expected to be supported by a much higher level of theories. Because the theory is an important part of the theoretical framework of a thesis, and it is usually discussed in the literature discussion section or as a separate section. $22 \%$ of the use of theory shows that there is a weakness in the connection of the theoretical framework with an appropriate theory. However, $17 \%$ of the theses mentioning a theory are master's theses, and 36\% are doctoral theses. Chi-square analysis shows a statistically significant relationship between the type of thesis and the use of theory (availablenone) $(\chi 2(1)=14.785, p<0.001)$. The use of more theories in doctoral theses comparing to master's theses, which aim to contribute new knowledge, can be considered as a natural result for doctoral theses.

Theses about user studies are the theses where theories are used most. Bertalanffy's general systems theory, Wilson's information behavior theory, and document life cycle theory are the theories used in thesis five or more times. These are followed by F. W. Taylor's scientific management theory, Kuhlthau's information search process, Ellis's information 
search theory, Krikelas' information behavior theory, and Dervin's sense-making theory. Bertalanffy's general systems theory, which provides a theoretical perspective for evaluating the library / information center as a system, is the most commonly used theory, but has a low degree of use (1.83) and is rather dealt with in the depth of background review. On the other hand, Wilson's theory of information behavior, Kuhlthau's information seeking process, Krikelas' information behavior, Ellis's information-seeking theory, Dervin's sense-making theory, which are based on library and information science, are discussed more intensely in the theses and are used in the degree of theory discussion (3). The unified theory of acceptance and use of technology and bibliometric theories, such as the Bradford distribution law and Zipf law (least effort theory), are the theories with the highest level of use (theory application level). The average degree of the use of theory is 2.6. Besides, it is determined that 75 theories are used in these theses and as Pierce (1992), and Pettigrew and McKechnie (2001) point out, most of these theses have a social science origin (58.6\%), and they are followed by library and information science $(30.6 \%)$ theses. Furthermore, as they can be recalled from the literature review, Pettigrew and McKechnie (2001) identified 100 different theories, and Jeong and Kim (2005) identified 80 different theories through their content analysis. Accordingly, it is observed that the researches in the library and information science in Turkey borrow from both various social science fields and use original theories of the field itself; among social sciences, especially psychology and disciplines of management are the sources of many theories used in the field.

The findings of this study represent the first step toward understanding the use of theory in library and information science research in Turkey and have some limitations. For example, theses without access are excluded from the scope of this research, and this can be considered as a limitation. However, the real limitation is that there is no data regarding the whole field research, and therefore to have a common judgment is very difficult. Although the theses are the main source of most of the research articles published in the field of library and information science in Turkey, a content analysis of the research articles that are planned for the future will provide a complete overview of the use of theory. There is a strong social institutionalization in Turkey regarding the field of library and information science, such as a research-based academic environment organized at the university level, professional publications, and a professional environment trained at the undergraduate and graduate levels. Such theoretical researches will contribute to the process of developing / improving the cognitive institutional level / intellectual identity of the field at the local and universal levels. 